\title{
Perception of the threat of War in Israel- implications for future preparedness planning
}

\author{
Moran Bodas ${ }^{1 *}$, Maya Siman-Tov², Shulamith Kreitler ${ }^{3}$ and Kobi Peleg ${ }^{1,2}$
}

\begin{abstract}
Background: It has been recently reported that the preparedness of the Israeli public to a war scenario is mediocre. These findings suggest a need to study the psychosocial mechanisms behind individual motivation to engage in preparedness behavior. One component of these mechanisms is the perception of threat. The purpose of this study is to portray the perception of the threat of war by the Israeli public and to deduce possible implications for resilience-promoting policies.

Methods: Portions of the data accumulated in a telephone-based random sampling of 503 households (representing the Israeli population) performed in October 2013 were utilized to examine the perception of the threat of war by Israelis. The questionnaire was used to examine the level of household preparedness, as well as attitudes toward perception of threat, preparedness responsibility, willingness to search for information, and sense of preparedness. Statistical analysis was performed to determine the correlations between different components of threat perception, and to evaluate the preparedness promoting features of specific perception factors.
\end{abstract}

Results: The data suggest that the perception of threat is influenced by different socio-demographic factors. In particular, age, religion and education seem to play an important role in the perception of threat. Compared to data collected almost a decade ago, the likelihood perception and threat intrusiveness rates were significantly reduced. The regression analysis suggests that perception of the severity of the impact on a family's routine and willingness to search for information, two known preparedness promoting factors, can be predicted by various socio-demographic and threat perception components.

Conclusion: The data suggest that the Israeli public, post the Second Lebanon War (2006) and the Gaza conflicts of 2009 and 2012, perceives the probabilities of war and being affected by it as diminished. The Israeli public demonstrates what can be considered as the unique characteristics of a war-victimized population. Implications for a future resilience-promoting policy were discussed.

Keywords: Emergency, Preparedness, War, Perception of threat, Israel

\section{Background}

Each year, emergency and disaster situations claim a heavy toll in human lives and economic loss [1]. The literature provides ample support for the claim that civilian populations, that are more prepared for emergencies also react better in the face of crisis and are less vulnerable to its adverse effects $[2,3]$. There is also evidence to

\footnotetext{
* Correspondence: moranbod@post.tau.ac.il

'The Department of Disaster Medicine, Sackler Faculty of Medicine, School of Public Health, Tel-Aviv University, P.O. Box 39040, Ramat Aviv, Tel-Aviv 69978, Israel

Full list of author information is available at the end of the article
}

support the viewing of the preparedness at the family level as a building block for communal resilience to emergencies [4-10]. In particular, this notion was found to be applicable to the Israeli public [11]. It is generally accepted that households engaging in emergency preparedness activities are potentially more resilient than others when confronted with an actual crisis, and therefore, are expected to require less medical care in the aftermath of the crisis $[7,8]$.

In an effort to explore this aspect in Israel, we reported in a separate publication that the preparedness of

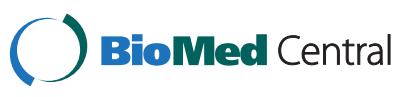


the Israeli public to a war scenario is mediocre [12]. The findings suggested that half of the Israeli population has complied with $50 \%$ or less of the civil defense recommendations for household preparedness to this threat. The results also suggested that in contrast to other populations, the Israeli public demonstrates little correlation between perception components and preparedness behavior. These findings led the proposal for an additional study of the perception of threat and its association to preparedness behavior, in order to better understand preparedness behavior. More specifically, in order to promote civilian resilience to emergencies, it is imperative that the psychosocial mechanisms behind individual motivation to engage in preparedness behavior be studied. Looking into the perception of threat could constitute a preliminary step in this direction.

A review of the literature in the field of emergency preparedness has identified several components of the perception of threat that were found to correlate with a household's level of preparedness [13-19]. Among these are: (1) the perception of the likelihood of the threat occurring in the near future; (2) the perception of the likelihood of personal harm (also known as threat intrusiveness); and (3) the perception of the severity of the threat to different elements of the social fabric. In addition, the perception of the responsibility to engage in preparedness behavior, specifically the tendency to assume personal responsibility, correlated with actual preparedness behavior [20-26].

Since these components were part of the questionnaire that was utilized for the national preparedness survey presented in Bodas et al. (2015) [12], the data accumulated from that survey was used to study the perception of the threat of war by the Israeli public in this study.

\section{Methods}

\section{Sample \& setting}

A random digital-dial (RDD) sample of telephone numbers drawn from the population registry of all area codes in Israel was conducted by a polling company between October 20-25, 2013. The telephone survey resulted in a sample of 503 households representing the population of the State of Israel (Table 1). The response rate was $23 \%$, and it is considered commonplace in telephonebased surveys [27]. The sampling took place amid rising tensions on the Syrian-Israeli border following the use of chemical weapons by the Syrian regime on the Syrian population, which intensified the aggressive posturing in the region. These rising tensions in turn led to a surge in the demand for gas masks in Israel and increased the level of awareness of the possibility of war among the Israeli public.

\section{Tools}

A questionnaire examining the components of threat perception and the preparedness of responders was developed based on an extensive literature review. The final version of the questionnaire was attained following preliminary studies that examined the clarity of the different items to different participants and a pilot study involving 226 people.

This current study deals with the first set of items included in this questionnaire. The perception variables measured and assessed were: (a) likelihood of war taking place in the next year or five years- two items; (b) the likelihood of being personally affected by war, i.e., injury or death- one item; (c) threat severity to different elements of the societal fabric, i.e., general society, community, family's routine, family property and family members (injury or death)- five items (Cronbach's Alpha: 0.854 ); and (d) responsibility for engaging in preparedness behavior by assigning responsibility to different factors e.g., state, military, local authority, community, family and self- six items (Cronbach's Alpha: 0.792). All of these were measured using multiple-choice items, in which a Likert-based scale was applied. Items requiring a more decisive answer by responders were assigned an even number of answers, thus eliminating a mid-scale option, which is known to distort the response distribution in some cases [28]. In odd scales, the optional answers were rated on a scale of 1 (very low) to 5 (very high), while in even scales, the middle answer was removed.

The willingness to search for information index was calculated as the mean score of an agreement with four statements: (Cronbach alpha: 0.629) (a) When I read or hear the news, I find interest mostly in news concerning a possible war in Israel in the near future; (b) I often look for preparedness information on my own initiative; (c) If I were to be invited to a preparedness seminar I would attend; (d) I am willing to accept a Home Front Command representative at my home to learn more about emergency preparedness.

\section{Statistical Analysis}

The statistical analysis of the results was performed using SPSS Version 22. The analysis included both descriptive and analytical methods, and the statistical tests were chosen according to the distribution of variables. The correlations between categorical variables were examined using a Chi-Square test, associations between categorical and continuous variables were examined with $T$-test for independent samples, and the Spearman Correlation Test was used to examine correlations between continuous variables.

In addition, regression analyses were employed to predict the perception of threat and the willingness to search 
Table 1 Socio-demographic distribution of studied sample $(\mathrm{N}=503)$

\begin{tabular}{|c|c|}
\hline Variable & $n(\%)$ \\
\hline \multicolumn{2}{|l|}{ Gender } \\
\hline Female & $260(51.7 \%)$ \\
\hline Male & $243(48.3 \%)$ \\
\hline \multicolumn{2}{|l|}{ Age } \\
\hline $18-30$ & $137(27.2 \%)$ \\
\hline $31-50$ & $192(38.2 \%)$ \\
\hline $51-70$ & $133(26.4 \%)$ \\
\hline $71-99$ & $40(7.9 \%)$ \\
\hline Missing & $1(<1.0 \%)$ \\
\hline \multicolumn{2}{|l|}{ Marital Status } \\
\hline Married & $319(63.4 \%)$ \\
\hline Other (single, divorced, widowed) & $184(36.6 \%)$ \\
\hline \multicolumn{2}{|l|}{ Birth place and immigration } \\
\hline Israel & $335(66.6 \%)$ \\
\hline Veteran immigrant (prior to 1991) & $104(20.7 \%)$ \\
\hline New immigrant (1991 onward) & $64(12.7 \%)$ \\
\hline \multicolumn{2}{|l|}{ Place of residence ${ }^{a}$} \\
\hline North or south & $230(45.8 \%)$ \\
\hline $\begin{array}{l}\text { Other (Center, Negev, greater Jerusalem, } \\
\text { Judea \& Samaria) }\end{array}$ & $272(54.1 \%)$ \\
\hline Missing & $1(<1.0 \%)$ \\
\hline \multicolumn{2}{|l|}{ Religion } \\
\hline Jews & $370(73.5 \%)$ \\
\hline Muslims & $85(16.9 \%)$ \\
\hline Others & 48 (9.6 \%) \\
\hline
\end{tabular}

Affiliation to religion

Secular

Traditional

Religious

Ultra-orthodox

No. of children under $18 \mathrm{y} / \mathrm{o}$

0 (None)

$1-3$

$\geq 4$

Education

$<\mathrm{K}-12$

High-School diploma

Vocational education

Academic education

Income

Less than average

Average

$272(54.1 \%)$

$135(26.8 \%)$

$69(13.7 \%)$

$27(5.4 \%)$

$263(52.3 \%)$

$200(39.7 \%)$

$40(8.0 \%)$

$126(25.0 \%)$

$129(25.7 \%)$

$54(10.7 \%)$

$194(38.6 \%)$

119 (23.7\%)

$125(24.8 \%)$
Table 1 Socio-demographic distribution of studied sample $(\mathrm{N}=503)$ (Continued)

\begin{tabular}{lc}
\hline More than average & $171(34.0 \%)$ \\
Missing & $88(17.5 \%)$ \\
\hline a For the purpose of this study, the geographical distribution of participants \\
was determined according to regions of past conflicts. The northern and \\
southern areas referred to in this research were those affected by the Second \\
Lebanon War (2006), and "Cast Lead" (2009) and "Pillars of Defense" \\
(2011) operations
\end{tabular}

for information. The first was examined through a multivariant, binary-logistic regression analysis to determine the odds-ratios of perception of threat components according to socio-demographic variables that were found to correlate with those components. This regression analysis was first carried out unadjusted for each independent variable correlating with the specific perception component, and then, adjusted for all variables. In this manner, the validity of the results could be assessed.

The second regression analysis was implemented using a multi-variant linear regression analysis to predict the willingness of participants to actively look for information on emergency preparedness. The regression was performed in Stepwise mode with two blocks: the first step included demographic variables, and the second step included components of the perception of threat. Only variables that were found to be associated with the dependent variable, following the negation of multiple colinearity, were introduced into the regression analysis.

In all statistical analyses performed, a p-value of 0.05 or less was determined as statistically significant.

\section{Results}

When asked to assess the likelihood of war irrupting in Israel, $22 \%$ and $40 \%$ of the sample predicted "high" or "very high" chances of such an occurrence happening within the next one or five years, respectively. Analysis carried out to establish the differences in the perception of likelihood between people of different socio-demographic background revealed that Jews and people under 40 years of age were more than twice likely to perceive the chances of war occurring within the next year as higher, compared to non-Jews and people over 40 years old. The same trend was observed for the five-year time frame in which differences were also observed between people with an academic education and average to low incomes, compared to non-academics and high earning households, but these were not significant in the multivariate adjusted analysis (Table 2).

When asked to estimate the likelihood of personal harm (i.e., injury or death) as a direct result of a war outbreak, the majority ( $55 \%$ ) of participants assessed it as low, compared to $33 \%$ who assessed this likelihood as high. Twelve percent refused to answer this particular question - the 
Table 2 Adjusted and unadjusted odds-ratio of threat perception components according to correlated socio-demographic variables $(N=503)$

\begin{tabular}{|c|c|c|c|c|c|}
\hline \multirow[t]{2}{*}{ Threat perception component } & \multirow[t]{2}{*}{ Variable $^{a}$} & \multicolumn{2}{|c|}{ Unadjusted } & \multicolumn{2}{|c|}{ Adjusted } \\
\hline & & OR & $95 \% \mathrm{Cl}$ & $\mathrm{OR}$ & $95 \% \mathrm{Cl}$ \\
\hline \multirow[t]{2}{*}{ Likelihood perception (1 year) } & Religion & 2.08 & $(1.375,3.143)^{++}$ & 2.16 & $(1.415,3.286)^{+++}$ \\
\hline & Age & 2.03 & $(1.418,2.900)^{+++}$ & 2.10 & $(1.456,3.017)^{+++}$ \\
\hline \multirow[t]{4}{*}{ Likelihood perception (5 year) } & Religion & 3.14 & $(2.063,4.768)^{+++}$ & 3.29 & $(2.050,5.297)^{+++}$ \\
\hline & Age & 1.70 & $(1.156,2.490)^{++}$ & 1.72 & $(1.099,2.697)^{+}$ \\
\hline & Education & 1.78 & $(1.193,2.668)^{++}$ & 1.61 & $(0.992,2.606)$ \\
\hline & Income & 0.59 & $(0.385,0.900)^{+}$ & 0.64 & $(0.409,1.014)$ \\
\hline \multirow[t]{3}{*}{ Severity perception (to society) } & Gender & 0.63 & $(0.413,0.956)^{+}$ & 0.62 & $(0.408,0.963)^{+}$ \\
\hline & Age & 1.71 & $(1.113,2.618)^{+}$ & 1.73 & $(1.120,2.680)^{+}$ \\
\hline & Place of birth & 2.81 & $(1.606,4.904)^{+++}$ & 2.87 & $(1.630,5.073)^{+++}$ \\
\hline Severity perception (to family routine) & Education & 1.62 & $(1.034,2.528)^{+}$ & NR & \\
\hline \multirow[t]{2}{*}{ Responsibility perception (Self) } & Place of residence & 0.57 & $(0.402,0.819)^{++}$ & 0.59 & $(0.410,0.837)^{++}$ \\
\hline & Children under 18 & 1.44 & $(1.010,2.047)^{+}$ & 1.40 & $(0.982,2.005)$ \\
\hline
\end{tabular}

anly variables found to correlate with the respective dependent variable are shown. The categorization of the independent variables are as follows: Religion: Jews = 1, other =0; Age: under $40=1$, over $\&$ including $40=0$; Education: academic $=1$, non-academics $=0$; Income: more than average $=1$, average or low $=0$; Place of residence: north or south $=1$, other $=0$; Gender: male $=1$, female $=0$; Place of birth: veteran immigrant or native Israeli $=1$, new immigrant $=0$; Children under 18: yes $=1$, no $=0 .+p<0.05++p<0.01+++p<0.001$

highest rate of refusal for a specific item in this study. Threat intrusiveness was reported more by residents of areas where conflicts had occurred previously, i.e., the north and south of Israel $(2.31 \pm 1.01)$, when compared with residents of other regions $(2.11 \pm 0.92)$ according to independent $T$-test $(\mathrm{t}=-2.12, \mathrm{df}=439, \mathrm{p}=.035)$. However, this finding was not statistically significant when examined in the binary-logistic regression (Table 2).

The results of the severity perception indicate a tendency to gravely predict the potential outcomes of a war occurring in Israel in the near future; $76.4 \%$ of the participants predicted high severity of the impact to the routine of life of the entire population, $69.2 \%$ to the routine of the local community, $75.8 \%$ to the routine of their families, $59.7 \%$ to their personal property, and $56.4 \%$ to themselves and their family members (i.e., injury or death). It is interesting to note that the percentage of refusal to answer a specific item increased, as the items progressed closer to the participant, ranging from a $2.4 \%$ refusal rate for the first item to $7.4 \%$ for the last item. As revealed by the independent samples $T$-test (data not shown), when looking into the influence of socio-demographic variables on the perception of severity, it was observed that women, people aged under 40 and native-born Israelis perceive the severity of war as higher, in comparison to men, people over 40 years old and immigrants, respectively. The regression analysis performed to explore these results found that men were about $60 \%$ less prone to perceive the threat more severely than women, and that being a native-born Israeli or a veteran immigrant is predicted to increase almost three-times the severity perception of the threat compared to a new immigrant (Table 2).

To complete the set of severity perception results, participants ranked the war scenario in comparison to other emergencies. The results suggest that the war scenario is perceived to be more severe than a major forest fire (24.6\% of opinionated participants replied the latter is worse), more severe than an economic crisis (35.8\%) and a terror attack (42.8\%), and less severe than a major earthquake (73.7 \%), a nuclear attack (87.9\%) and a chemical attack (89.3\%).

When asked to assign different organizations with the responsibility of engaging in preparedness efforts, $54.5 \%$ of participants attributed high or very high responsibility to themselves, $57.5 \%$ to their families and local communities (each), $76.5 \%$ to their local authority, $89.3 \%$ to the military and civil defense authorities, and $89.9 \%$ to the government.

According to independent samples T-test (data not shown), residents living outside of previous conflict areas (i.e., Center, Negev, Greater Jerusalem, and Judea \& Samaria districts) and parents of children under 18 years of age were more likely to assume a personal responsibility for preparedness than residents of the north and south and participants without children under 18 years of age. These findings were also partially supported by the regression analysis, with the exception that having children under 18 years old was not found to be statistically significant in the multivariate adjusted analysis (Table 2).

Finally, correlations were observed between most components of the perception of threat, as well as between 
Table 3 Spearman Correlations of threat perception components of war in Israel $(N=503)$

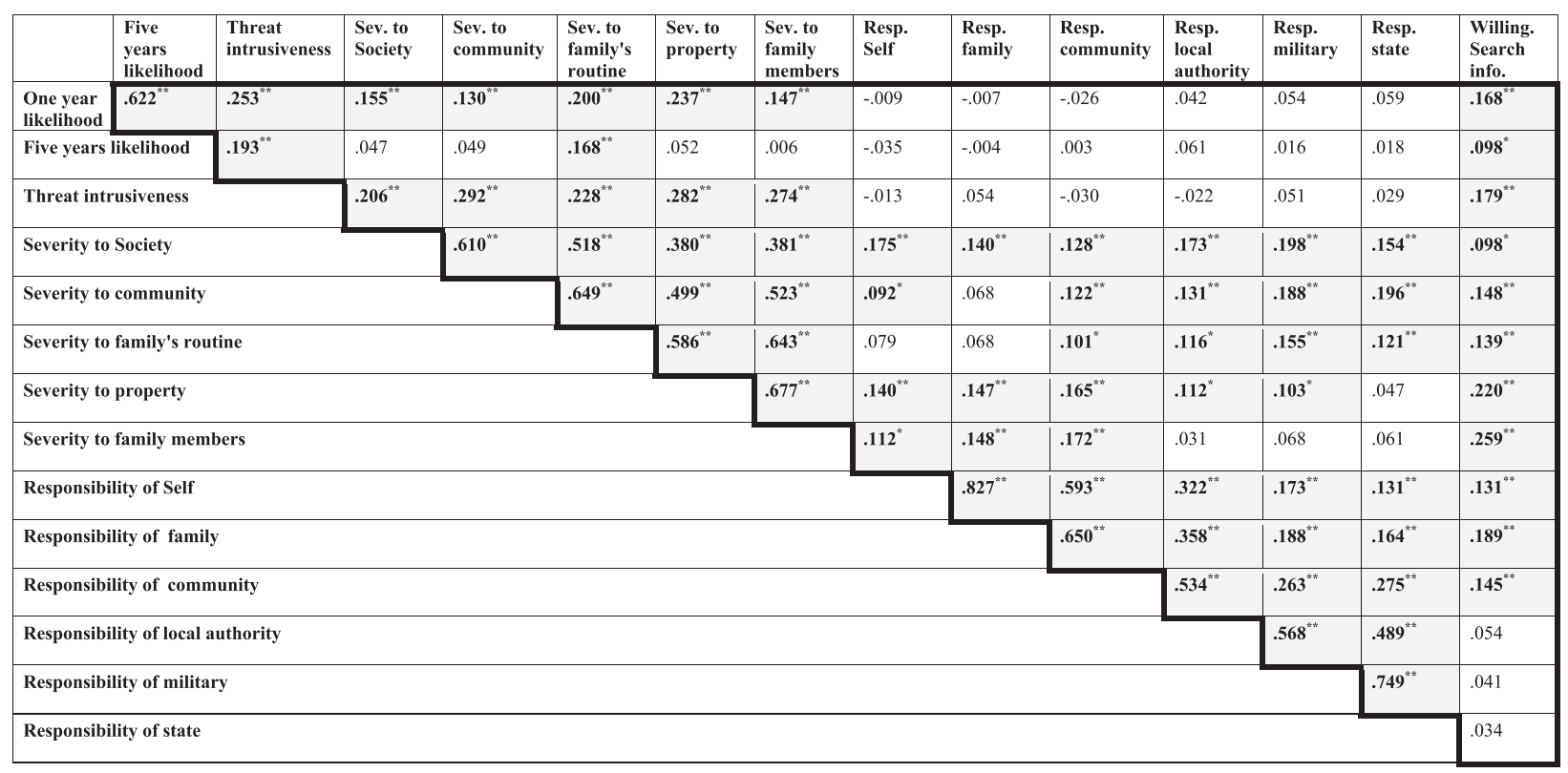

Sev Severity; Resp Responsibility; Willing. search info. Willingness to search for information. Statistically significant results are highlight

* Correlation is significant at the 0.05 level (2-tailed)

${ }^{* *}$ Correlation is significant at the 0.01 level (2-tailed)

the perception of responsibility and the severity of the threat (Table 3).

In addition, it is interesting to explore the predictors of the perceived severity of impact on a family's routine and willingness to search for information, factors that were reported to correlate with preparedness behavior in a previous publication [12]. The regression analysis suggested that the model behaves differently for new immigrants and native born or veteran immigrants. A stratified examination of the data indicated that while the severity perception among new immigrants cannot be effectively predicted by other variables, it could be predicted among native Israelis by education and income levels (in an adjusted analysis). Holders of an academic degree were three times more likely to perceive the greater severity of the threat than participants with a non-academic education $(\mathrm{OR}=3.33$ 95\%CI 1.731, $6.405 p<.001)$. Similarly, higher earning individuals were almost twice as likely to perceive greater severity than average to low income earning individuals $(\mathrm{OR}=1.824 .95 \% \mathrm{CI} 1.060,3.137 p=.03)$.

The regression analysis performed to predict the willingness to actively search for information revealed that $22.4 \%$ of the dependent variable can be predicted by religion, affiliation to religion, education, age, perception of the threat likelihood (within the next year) and perception of threat severity to self and family members. The predominant variable in predicting willingness to search for information was the latter $(\beta=0.309)$ (Table 4).

\section{Discussion}

The purpose of this study was to explore the perception of the threat of war by the Israeli public. The motivation behind the research arises from evidence provided by the literature for association between the perception of threat and preparedness behavior [13-19]. However, this does not seem to be the case with the Israeli population,

Table 4 Results of final step of linear regression analysis to predict willingness to search for information

\begin{tabular}{lllll}
\hline Variable & Categories & $\beta$ & $p$-value & $\mathrm{R}^{2}$ \\
\hline Religion & 0 - other & -.263 & .000 & .224 \\
& 1 - Jewish & & & \\
Affiliation to religion & 0 - religious & -.135 & .006 & \\
& 1 - secular & & & \\
Education & 0 - non- & -.161 & .001 & \\
& academic & & & \\
& 1 - academic & & & \\
Age & Cont. & .145 & .003 & \\
Severity to self and family & Cont. & .309 & .000 & \\
members & & & & \\
One year likelihood & Cont. & .147 & .003
\end{tabular}

Regression analysis performed in stepwise mode with two block. The variables entered into the analysis were: First block - gender, age, religion, affiliation to religion, education and income. Second block - one year likelihood, five years likelihood, threat intrusiveness, severity to society, severity to community, severity perception to family's routine, severity to property, and severity to self and family members 
at least not for the war scenario. In a recent publication based on the same database presented in this paper, it was demonstrated that the Israeli public did not exhibit the correlation reported in the literature between perception of threat and preparedness, but for one exception concerning the perceived severity of impact on the family's routine [12]. Given this seeming disparity between the threat perception components and the preparedness behavior, one could argue that there is no reason to further explore the perception of threat by the Israeli public because no meaningful conclusions can be drawn for policymaking. Yet, as the findings of this study suggest, there is much to be learned from the analysis of the perception of threat by the Israeli public concerning better approaches to promote public resilience.

It is interesting to note that the Israeli public demonstrates unique patterns of threat perception, when compared to those reported for other populations. On the one hand, Israelis tend to estimate the likelihood of war in the near future as low. In actuality, this assessment turned to be false with the eruption of the July 2014 operation in Gaza, less than a year following our telephone-based survey. On the other hand, Israelis tend to estimate the severity of the threat as high, with more than half of the sample anticipating severe outcomes for themselves, their family members and their properties. For both variables, i.e., the perception of likelihood and the perception of severity, younger people tend to have a more pessimistic view of the threat. Nevertheless, explaining this phenomenon by "young and afraid" simply cannot cut it because the data also suggest a complimentary trend, according to which the more experienced a person is with the threat, the more he or she perceives it as a threat. This is demonstrated through the higher rates of the perception of severity among native-born Israelis, and the higher threat intrusiveness among residents of regions affected by prior conflicts; both represent groups that endured the threat for longer extents than their counterparts did.

The above hypothesis regarding the unique characteristics of the Israeli public's perception of threat is supported by findings reported by Lahad, Shcham \& Shcham (2009) [29], who have examined the Jewish and Arab population in northern Israel following the Second Lebanon War. The authors concluded that communities enduring persisting hardship such as war and terrorism, have less faith in authorities' capabilities to support preparedness and are less likely to anticipate retrieval of normalcy to their everyday lives. Mistrust in authorities was already reported as counterproductive to individual preparedness behavior [30].

Perhaps, one of the most important findings of this research emerges from the changes observed in the patterns of threat perception by the Israeli public in recent years. In 2005, Kirschenbaum noted that $66 \%$ of his then studied sample of the Israeli public reported perceiving a medium to high chance of war occurring in Israel in the "near future." [17] However, less than a decade later, we observed a reduction in the likelihood perception with only $49 \%$ of the current sample reporting similar likelihood rates (in adjusted scales). According to the Chi-square test $\left(\mathrm{X}^{2}=48.081, \mathrm{df}=2, p<.001\right)$, this difference is statistically significant. In line with the Chi-square test $\left(\mathrm{X}^{2}=5.95, \mathrm{df}=1, p=.015\right)$, threat intrusiveness rates reported in the current study (33\%) were significantly lower than those reported by Kirchenbaum in 2005 (44 \%). The data suggest that the Israeli public, post the Second Lebanon War (2006) and the Gaza conflicts of 2009 and 2012 perceives the probabilities of war and being affected by it as diminished. Attempting to generalize this conclusion, these results suggest that kept under constant reminder of a threat, a given population might develop apathy or indifference toward it.

We suggest that the reduction in threat intrusiveness can be explained as the result of habituation to armed conflicts, a process in which the Israeli public is desensitized to the threat by observing a relatively small toll on Israeli lives. A similar notion was proposed by Dov Waxman (2011) for terrorism [31]. This phenomenon is backed in numbers. According to official data [32-34]: (a) during the 33 days of the Second Lebanon War (2006), 41 civilians died and 2000 were injured. Approximately 4000 rockets were fired at the northern part of the country, thus, generating a death rate of one person per 100 rockets; (b) during the 22 days of operation "Cast Lead" (2009) in Gaza, three civilians were killed and 183 were injured as a result of the 536 rockets fired during this conflict - a death rate of 0.6 persons per 100 rockets; (c) in the eight days of operation "Pillar of Defense" (2012) in Gaza, 4 civilians were killed and 241 injured as a result of the 1264 rockets not intercepted by the "Iron Dome" missile defense system. This constitutes a death rate of 0.3 persons per 100 rockets. A similar trend can be observed in the rates of injured persons. Although not relevant for the data reported in this study performed in 2013, the trend continues for the 2014 Gaza conflict, in which the death rate dropped to 0.14 persons per 100 rockets not intercepted.

The data provided above suggest that the Israeli public, possibly reassured by a technological advancement in the defense arena (e.g., the "Iron Dome" missile defense system), have grown accustomed to the threat of hightrajectory weapons, and perceive them less-and-less as a personal risk. Yet, this should also be considered for its backfiring potential, since the same apathy can lead people to place themselves in harm's way instead of following lifesaving instructions. This phenomenon was already observed during the 2009, 2012, and 2014 Gaza conflicts, in which civilians were either killed or injured 
because of their disregard or non-adherence to emergency behavior instructions issued by the civil defense authority.

While the reduction in threat intrusiveness since 2005 might be explained by the habituation effect, it is much more difficult to provide an explanation for the parallel reduction in the perception of the likelihood of the threat. This issue is further complicated in light of the tendency to expect the worst out of the war scenario, as demonstrated in the severity perception data. The findings here seem to be conflicting. On the one hand, the majority of Israelis do not foresee a looming war in the near future; however, they also hold a grave perception of the outcomes of such war if it indeed occurred. In order to explain the reduced rates of likelihood perception, one should first explain the findings of the severity perception.

This study suggests that the Israeli public is anticipating severe outcomes of a war taking place in Israel in all layers of its societal fabric, including the impact on the family's routine. Despite enduring this threat for decades, the notion of war remains intimidating to most Israelis. It is therefore not surprising that responders tend to alienate themselves from the risk. Responders in our survey increasingly refused to answer items as they became more specific to their personal well-being. Potentially, this could be explained as a basic mechanism of denial, and could account for much of the findings presented in this paper: a perception of a severe threat may lead to denial-based coping mechanisms that are exhibited in a reduced perception of likelihood. This serves to further illustrate the difficulty in motivating the public to engage in preparedness behavior. In this context, it is also interesting to note that people residing in areas affected by armed conflict up to 2013, i.e., the north or south of Israel, are also less keen on assuming personal responsibility for preparedness behavior. This finding suits the suggested explanation that repeated experience with the threat could be counterproductive in promoting individual motivation for an engagement in preparedness behavior.

The findings of this study suggest that the association reported in the literature between the perception of threat and preparedness behavior is probably mediated by other factors, which are yet to be fully identified. A similar notion was proposed by Rüstemli and Karanci (2010), who examined the preparedness behavior among earthquake-victimized population in Turkey [35]. The authors conclude there:

These results suggest that protective behavior in victimized populations is determined essentially by fear and belief in personal control rather than severity of prior experience and cognition related to the perceived severity and occurrence of future hazards. (p. 99)

\section{Implications for policymaking}

In a separate publication [12] based on the same database examined in this paper, we reported correlates of preparedness behavior in the Israeli public. It was reported that $15.4 \%$ of the variance in preparedness behavior, i.e., the public's compliance rate with the civil defense recommendations, can be explained by place of birth, place of residence, sense of preparedness, willingness to search for information, and the perceived severity of impact on a family's routine. Out of these five predictors, only the last two can be considered as targets for potential intervention policies.

In this current study, it is demonstrated that the perceived severity of impact on a family's routine could be predicted through levels of income and education (for native-born Israelis). However, it should be noted that our previous study reported a negative correlation between severity perception and preparedness behavior [12]. Since we cannot and do not wish to propose to promote public resilience by increasing the severity perception at the expense of reducing literacy rates or income, we cannot offer a meaningful recommendation on this aspect.

Nevertheless, there is much to be learned from examining the data around the willingness to search for information. Other publications support the beneficial attributes of willingness to search for information [15, 26, 36, 37]. More recently, a national survey performed by the U.S. Federal Emergency Management Authority (FEMA) in 2012 found that information aware respondents were more likely than unaware respondents to report that they had updated their supplies and had a household emergency plan [38]. In this current study, the regression analysis suggests that this preparedness-promoting factor can be predicted by several socio-demographic variables, but also by perceptions of likelihood and severity. In fact, severity perception to oneself and family members was the most predictive factor of willingness to search for information $(\beta=0.309)$. In the face of it, this seems to contradict the previously reported negative effect observed for severity perception on preparedness behavior [12], because it suggests that having a graver perception of threat outcomes can lead to information seeking, which is predicted to increase engagement in preparedness behavior. Since the negative correlation reported between severity perception and preparedness [12] did not point out which is the cause and which is the effect, the latest findings reported in this study suggest that increased preparedness leads to a decrease in severity perception, almost certainly due to a heightened sense of preparedness. A full picture can now 
be proposed - increased severity perception of the threat to oneself and family members promotes information seeking, which is expected to result in actual preparedness behavior. Once this behavior is performed, the individual appraisal of increased familial preparedness leads to a sense of preparedness that decreases the perceived severity of impact on a family's routine. These findings suggest that a possible target for risk communication strategies should be promoting individual assessment of personal and kin risk prior to and following preparedness behavior.

Lastly, investing in the promotion of public resilience to emergency can translate into reduced demands for healthcare in the aftermath of a crisis. This is probably true for the provision of both medical healthcare and mental healthcare. Drawing support from the literature in the field $[2,3,7,8]$, we conclude that a more resilient Israeli public will be able to better cope in the face of adversity. Policy makers should therefore regard the promotion of resilience as an additional means of promoting public health through preventive measures.

\section{Conclusions}

The findings of this study suggest that the Israeli public demonstrates unique patterns of perception of the threat of war. Israelis underestimate the likelihood of war, while at the same time overestimate its adverse outcomes. An analysis of these perception patterns, in particular, in comparison to the data provided on the Israeli public from less than a decade ago suggests a possible combined mechanism of denial and habituation to the threat. The findings of this study illustrate the difficult playground set for preparedness promoters such as civil defense authorities.

Since populations demonstrating higher resilience are better fitted to cope with the adverse effects of crisis, policy makers striving to promote public health should also promote resilience. Nonetheless, a population is only as resilient as its members are. It is therefore imperative to study the psychosocial mechanisms behind individual motivation to engage in preparedness behavior in order to better understand how to promote public health in this aspect. Once these mechanisms are deciphered, a proper strategy for risk communication and public engagement can be generated.

\section{Competing interests}

The authors declare that they have no competing interests.

\section{Authors' contributions}

MB has oversaw the data acquisition process, has made the literature review and has drafted the body of the paper. MST has made substantial contributions to conception and design, statistical analysis and critically revising of the paper. SKhas critically revised the paper and has given final approval of the version to be published. KP has critically revised the paper and has given final approval of the version to be published.

\section{Authors' information}

Prof. Kobi Peleg, MPH, PhD

Prof. Kobi Peleg is the director of the National Center for Trauma \& Emergency Medicine Research, The Gertner Institute for Health Policy \& Epidemiology, and the head of the Disaster Medicine Department, and the head of the Executive Master Program for Emergency and Disaster Management, School of Public Health, Tel-Aviv University.

Prof. ShulamithKreitler, MA, PhD

Professor at Tel Aviv University \& Sheba Hospital. For over 40 years, she has been full professor of psychology at Tel-Aviv University. At present, she is professor emeritus at Tel-Aviv University and continues her active career teaching at Tel-Aviv University, and occasionally in different universities in Europe. Prof. Kreitler is a certified clinical psychologist and a certified health (medical) psychologist. She serves as the Head of the Psycho-oncology Research Center at Sheba - Tel Ha'Shomer Hospital. In the past, she also served as the Head of Psycho-oncology Unit at Tel Aviv Medical Center. Her major expertise is in motivations of behavior, meaning processes, cognition, and health psychology. She has written over 200 articles in peer-reviewed journals and has published 15 books.

Maya Siman-Tov, MA

Maya Siman-Tov is a PhD student in the school of public health, Haifa University, is a senior researcher in the Israel National Center for Trauma and Emergency Medicine Research at Gertner Institute for Epidemiology and Health Policy Research since 2006. Her research interests include trauma injuries, child injuries, road traffic related injuries and violence related injuries.

Moran Bodas, MPH

Moran Bodas is a PhD student in the Disaster Medicine Division, Sackler Faculty of Medicine, Tel-Aviv University. His research focuses on deciphering psychosocial components of individual preparedness behavior in the hope this understanding will help promote public resilience in emergencies. He graduated from the Multidisciplinary Program for Emergency and Disaster Management in Tel-Aviv University cum laude. He was previously involved in national preparedness to non-conventional threats (chemical, biological and radiological) within the Ministry of Defense.

\section{Acknowledgements}

This research was performed as part of a thesis dissertation of MB in supervision of SK and KP. The authors acknowledge the financial support from the Department of Disaster Medicine at the School of Public Health, Sackler Faculty of Medicine, Tel-Aviv University.

\section{Author details}

'The Department of Disaster Medicine, Sackler Faculty of Medicine, School of Public Health, Tel-Aviv University, P.O. Box 39040, Ramat Aviv, Tel-Aviv 69978, Israel. ${ }^{2}$ Sheba Medical Center, Israel National Center for Trauma \& Emergency Medicine Research, The Gertner Institute for Epidemiology and Health Policy Research, Tel Hashomer, Ramat-Gan, Israel. ${ }^{3}$ Psychoncology Research Center, Sheba Medical Center, Gordon Faculty of Social Sciences, School of Psychological Sciences, Tel-Aviv University, Tel Hashomer, Ramat-Gan, Israel.

Received: 23 December 2014 Accepted: 6 June 2015

Published online: 01 October 2015

\section{References}

1. United Nations. Strategic Framework 2025 - Work Program 2012-2015. UNISDR website. http://www.unisdr.org/files/23291_1101657inteng.pdf. October 2011. Accessed December 4, 2013.

2. Peek $L A$, Mileti DS. The history of disaster research. In: Bechtel RB, Churchman A, editors. Handbook of environmental psychology. New-York: John Wiley \& Sons Inc; 2002. p. 511-24.

3. Hemond $Y$, Robert B. Preparedness: the state of the Art and future prospects. Dis Prev Manag. 2012;21(4):404-17.

4. Trost J, Hultaker O. Introduction - family and disaster (special issue). Intl J Mass Emerg Dis. 1983;1:7-18.

5. Drabek TE. Human responses to disaster: an inventory of sociological findings. New-York, NY: Springer; 1986.

6. Kirschenbaum A. The mother Hen effect. In: Kirschenbaum A, editor. Chaos organization and disaster management. New York: Marcel Dekker; 2003. p. 177-213.

7. Coffman S. Parents' struggle to rebuild family life after hurricane Andrew. Issues Ment Health Nurs. 1996;17:353-67. 
8. Patterson JM. Integrating family resilience and family stress theory. J Marriage Fam. 2002;64:349-60.

9. Gerrity ET, Steinglass P. Relocation stress following catastrophic events. In: Ursano RJ, editor. Terrorism and disaster: individual and community mental health interventions. New York: Cambridge University Press; 2003. p. 259-86.

10. Miller L. Family therapy of terroristic trauma: psychological syndromes and treatment strategies. Am J Fam Ther. 2003;31:257-80.

11. Kirschenbaum A. Families and disaster behavior: a reassessment of family preparedness. Int J Mass Emerg Dis. 2006;24:111-43.

12. Moran Bodas, Maya Siman-Tov, Shulamith Kreitler and Kobi Peleg. Assessment of Emergency Preparedness of Households in Israel for War-Current Status. Disaster Medicine and Public Health Preparedness. 2015;9(4):382-390

13. Lindell MK, Perry RW. Household adjustment to earthquake hazard: a review of research. Environ Behav. 2000;32(4):461-501.

14. Lindell MK, Prater CS. Risk area Residents' perception and adoption of seismic hazard adjustments. J Appl Soc Psychol. 2002;32(11):2377-92.

15. Turner RH, Nigg JM, Paz D. Waiting for disaster: earthquake watch in California. California: University of California Press; 1986.

16. Burns R, Sullivan P. Perceptions of danger, risk taking, and outcomes in a remote community. Environ Behav. 2000:32(1):32-71.

17. Kirschenbaum A. Preparing for the inevitable: environmental risk perceptions and disaster preparedness. Intl J Mass Emerg Dis. 2005;23(2):97-127.

18. Lindell MK, Hwang SN. Households' perceived personal risk and responses in a multihazard environment. Risk Anal. 2008:28(2):539-56.

19. Miceli R, Sotgiu I, Settanni M. Disaster preparedness and perception of flood risk: a study in an alpine valley in Italy. J Environ Psychol. 2008;28:164-73.

20. Garcia EM. Earthquake preparedness in California: a survey of Irvine residents. Urban Res. 1989:5:15-9.

21. Mulilis JP, Duval TS. Negative threat appeals and earthquake preparedness: a person-relative-to-event Pre model of coping with threat. J Appl Soc Psychol. 1995;25:1319-39.

22. Lindell MK, Whitney DJ. Correlates of household seismic hazard adjustment adoption. Risk Anal. 2000;20(1):13-26.

23. Duval TS, Mulilis JP. A person-relative-to-event (PrE) approach to negative threat appeals and earthquake preparedness: a field study. J Appl Soc Psychol. 1999;29(3):495-516

24. Ballantyne M. Information on volcanic and earthquake hazards: the impact on awareness and preparation. New Zealand: Institute of Geological \& Nuclear Sciences; 2000

25. Paton D, Smith LM, Johnston D. Volcanic hazards: risk perception and preparedness. N Z J Psychol. 2000;29(2):86-91.

26. Perry RW, Lindell MK. Volcanic risk perception and adjustment in a multi-hazard environment. J Volcanol Geotherm Res. 2008;172(3):170-8.

27. Johnson T, Owens L. Survey response rate reporting in the professional literature, American association for public opinion research - section on survey research methods - 58th annual meeting. 2003. p. 127-33.

28. Kulas JT, Stachowski AA, Haynes BA. Middle response functioning in likert-responses to personality items. J Bus Psychol. 2008;22(3):251-9.

29. Lahad M, Shacham M, Shacham Y. The impact of the 2006 Lebanon War on both traumatic experience and resiliency of Jews and Arabs in north Israel - a longitudinal study. In: Azaiza F et al., editors. Welfare, health and education services in emergency times. Haifa, IL: Pardes Publication; 2010. p. 117-45.

30. Kohn S, Eaton JL, Feroz S, et al. Personal disaster preparedness: an integrative review of the literature. Disaster Med Public Health Prep. 2012;6(03):217-31

31. Waxman D. Living with terror, not living in terror: the impact of chronic terrorism on Israeli society. Perspectives Terror. 2011;5(5-6):4-26.

32. Israel State Comptroller and Ombudsman. Home Front Preparedness and Functioning during the Second Lebanon War - Full report. July 18, 2007; Available at: http://old.mevaker.gov.il/serve/contentTree.asp?bookid= 493\&id $=188 \&$ contentid=9063\&parentcid $=9061 \&$ bctype $=1 \& \mathrm{sw}=1366 \& \mathrm{hw}=698$

33. Israel Security Agency database: One Year to "Cast Lead" Operation. TelAviv, Israel: December 2009; Available at: https://www.shabak.gov.il/ publications/archive/oferet/Pages/tlul11-1-09.aspx

34. Israel Security Agency database: Operation "Pillar of Defense". Tel-Aviv, Israel: December 2012; Available at: http://www.shabak.gov.il/heritage/affairs/ Pages/OperationPillarofDefense.aspx

35. Rüstemli A, Karanci N. Correlates of earthquake cognitions and preparedness behavior in a victimized population. J Soc Psychol. 1999;139(1):91-101.
36. Mileti DS, Fitzpatrick C. The causal sequence of risk communication in the parkfield earthquake prediction experiment. Risk Anal. 1992;12:393-400.

37. Mileti DS, Darlington JD. The role of searching in shaping reactions to earthquake risk information. Soc Probl. 1997:44:89-103.

38. U.S. Federal Emergency Management Authority. Personal Preparedness in America: Findings from the 2012 FEMA National Survey. Washington, DC: July 2013; Available at: http://www.fema.gov/media-library-data/14091465480707c8016a9a41b65b2c584ffacdbe4f920/2012_FEMA_National_Survey_Report_ FINAL_508_v11.pdf

\section{Submit your next manuscript to BioMed Central and take full advantage of:}

- Convenient online submission

- Thorough peer review

- No space constraints or color figure charges

- Immediate publication on acceptance

- Inclusion in PubMed, CAS, Scopus and Google Scholar

- Research which is freely available for redistribution

Submit your manuscript at www.biomedcentral.com/submit 